\title{
Neuer Leiter der AOTD-Geschäftsstelle
}

Christof Müller

\section{Zum 1. Juni 2019 beginnt George Clay als neuer Leiter der Geschäftsstelle der AOTrauma Deutschland (AOTD).}

Der AOTrauma Deutschland ist es gelungen, mit George Clay einen langjährigen Mitarbeiter der AOTrauma Europa für die Leitungsposition der AOTD zu gewinnen. George Clay war davor 9 Jahre in Davos und bei AOTrauma Europe \& Southern Africa tätig als „Educational Development Project Manager“ für die Regionen Deutschland, Zentral- und Osteuropa, Israel sowie südliches Afrika. Er kennt die internen Prozesse und Organisationsstruktur der AOTrauma. Er bringt ein ausgezeichnetes Netzwerk sowohl zu den Mitarbeitern der AO Foundation als auch der führenden ärztlichen Vertreter und Kursleiter in den Teilen Europas mit, für die er verantwortlich war. Besonders wichtig sind seine Kenntnisse der Schulungsveranstaltungen der AOTrauma in Deutschland.

George Clay wurde 1976 in Deutschland geboren, verbrachte aber den größten Teil seiner Kindheit in Sierra Leone. Später legte er in seiner Heimatstadt Freiburg das Abitur ab. Nach einem 6-monatigen Auslandspraktikum in Südafrika zog er nach Berlin, wo er an der Fachhochschule für Wirtschaft seinen Abschluss als Diplom Betriebswirt erlangte. Die ersten beruflichen Erfahrungen sammelte er in Südafrika, wo er zunächst mit der Leitung des Kreuzfahrtgeschäfts der TUI für das südliche Afrika betraut war. Darauf folgte die Tätigkeit als Finanzverwalter der Friedrich-Naumann-Stiftung Südafrika. Nebenbei arbeitete er 2010 als Volunteer für die FIFA Fußball-Weltmeisterschaft in Südafrika. Im Jahr 2010 wechselte er zur AO nach Davos.

George Clay wird von Freiburg aus arbeiten, um die Zusammenarbeit mit dem Kursteam in Umkirch zu intensivieren.

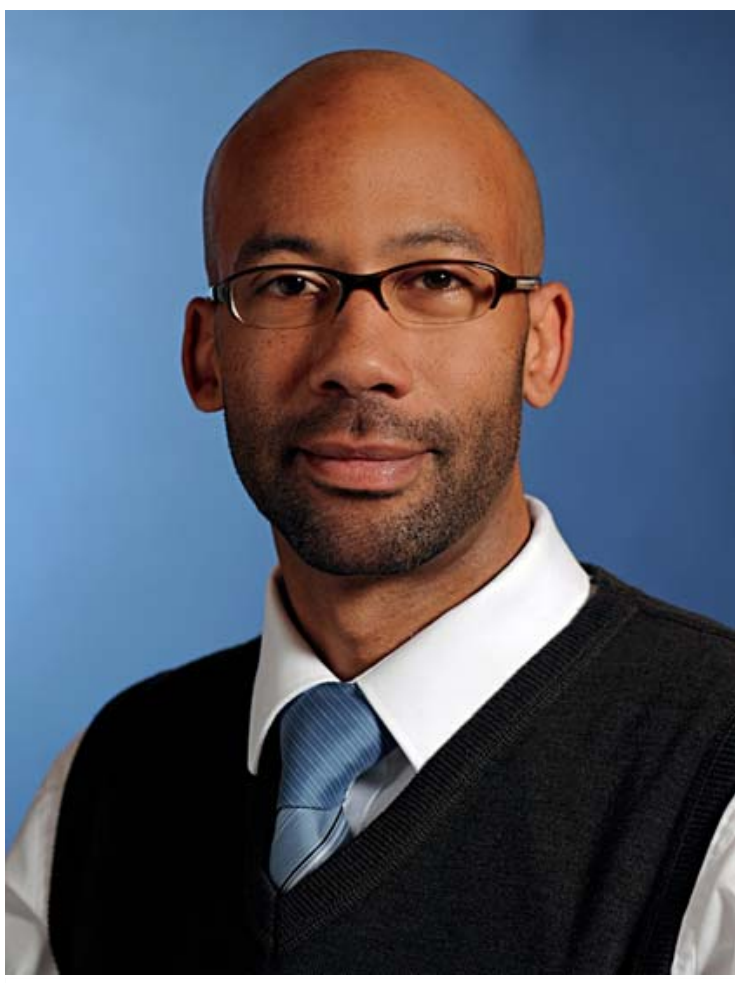

- Abb. 1 George Clay. Quelle: George Clay

Bibliografie

DOI https://doi.org/10.1055/a-0953-5519

OP-JOURNAL 2019; 35: 201 @ Georg Thieme Verlag KG Stuttgart · New York ISSN 0178-1715 